\title{
Overexpression of sigma-1 receptor inhibits ADAM10 and ADAM17 mediated shedding in vitro
}

Juan Li, Bin Liu, Xiaofei Gao, Zhixing Ma, Tianyi CaoSong, Yan-ai Mei, Yufang Zheng

School of Life Sciences, Fudan University, Shanghai 200433, China

$\bowtie$ Correspondence: zhengyf@fudan.edu.cn

Erratum to: Protein Cell 2012, 3(2): 153-159

DOI $10.1007 /$ s13238-012-2006-9

Two mistakes in Fig. 3A and 4A, respectively, were made due to typesetting errors.

Figure $3 \mathrm{~A}$, on the left column of page 156 , should be corrected as follows.

A

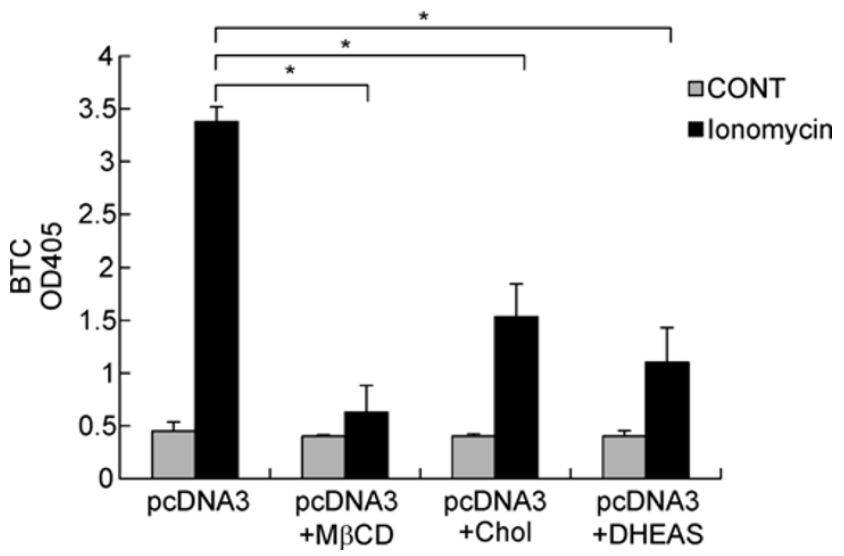

Figure 4A, on the left column of page 157, should be corrected as follows.

A

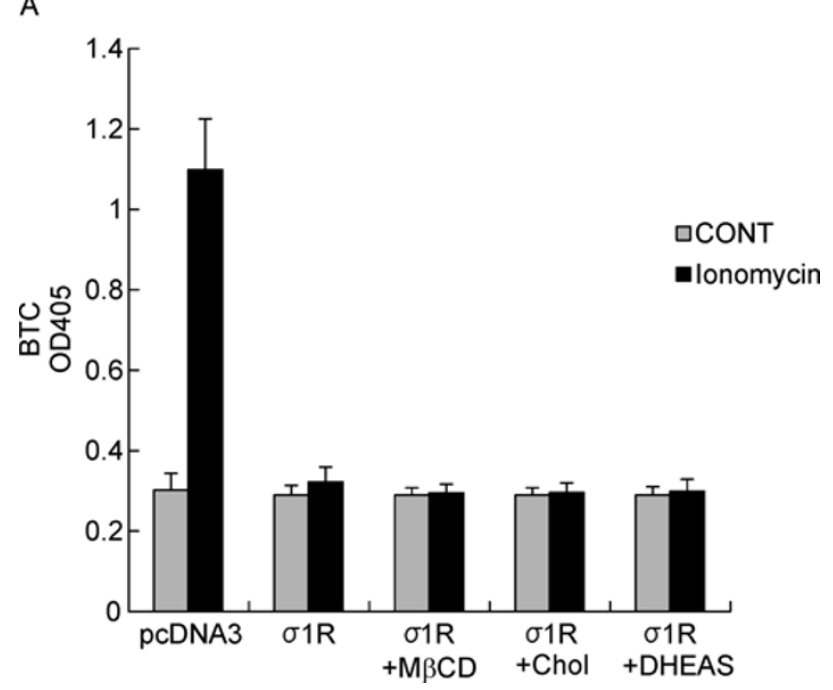

The online version of the original article can be found at http://dx.doi.org/10.1007/s13238-012-2006-9 